\title{
A SEGURANÇA ALIMENTAR E NUTRICIONAL (SAN) E A CONSERVAÇÃO DOS ECOSSISTEMAS: A INTERSETORIALIDADE NAS POLÍTICAS PÚBLICAS ${ }^{1}$
}

\author{
Kathleen Hodgson Weintraub ${ }^{2}$ \\ Camila Gonçalves de Oliveira Rodrigues ${ }^{3}$ \\ Katia Cilene Tabai ${ }^{4}$
}

\begin{abstract}
Resumo: No contexto global, no qual o modelo predominante de produção alimentar é uma das principais causas de degradação ecossistêmica, esta pesquisa buscou refletir sobre a interface entre políticas públicas de segurança alimentar e nutricional (SAN) e conservação dos ecossistemas. Foram realizados o levantamento e a análise de políticas públicas brasileiras nos dois campos, salientando as lacunas de intersetorialidade dentro e entre eles, além dos desafios para sua implementação. Como forma de compreender as possibilidades de aplicação das políticas estudadas, o trabalho enfatizou o bioma Mata Atlântica, com destaque para sua legislação específica. A análise empreendida neste artigo evidencia que as políticas de SAN no Brasil são mais intersetoriais e tendem a ser mais inclusivas da perspectiva ambiental do que o inverso. $O$ artigo apresenta ainda uma perspectiva de integração que tem sido incentivada na agenda internacional a partir da utilização do conceito de serviços ecossistêmicos e dos benefícios da conservação dos ecossistemas para a sociedade.

Palavras-chave: Políticas públicas, Segurança alimentar e nutricional, Unidades de conservação, Agricultura familiar, Serviços ecossistêmicos.
\end{abstract}

\section{FOOD AND NUTRITIONAL SECURITY AND THE CONSERVATION OF ECOSYSTEMS: INTERSECTORIALITY IN PUBLIC POLICIES}

\begin{abstract}
In the global context, in which our current food system is one of the main causes of ecosystem degradation, this research sought to reflect on the interface between public policy on Food Security and Nutrition (FSN) and ecosystem conservation. Initially, a survey and analysis of Brazilian public policies from both areas were carried out, highlighting the intersectoral gaps within and between spheres, in addition to the challenges for their implementation. As a way of understanding the possibilities of applying the studied policies, the work focused on the Atlantic Forest biome, with emphasis on its specific legislation. The analysis undertaken in this article shows that SAN policies in Brazil are more intersectoral and tend to be more inclusive from an environmental perspective than vice versa. The article also presents an integrative perspective that ha been promoted on the international agenda that uses the concept of ecosystem services and the benefits of the conservation of ecosystems for society.
\end{abstract}

Keywords: Public policy, Food security and nutrition, Protected areas, Family agriculture,Ecosystem services.

\footnotetext{
${ }^{1}$ Este artigo foi baseado parcialmente na dissertação de mestrado da primeira autora, Kathleen Weintraub, a saber, Baixada viva: manejo sustentável da jaqueira para fins alimentares e as perspectivas da integração das políticas públicas ambientais e de segurança alimentar, 2020, no Programa de Pós-graduação em Práticas de Desenvolvimento Sustentável - Universidade Federal Rural do Rio de Janeiro.

${ }^{2}$ Mestre em Ciências pelo Programa de Pós-Graduação em Práticas em Desenvolvimento Sustentável - PPGPDS. Universidade Federal Rural de Rio de Janeiro - UFRRJ. Graduação em Ciências Políticas e Saúde Pública Global pela Universidade de Harvard (2014), em Cambridge, Massachusetts. Grupo de Pesquisa do CNPq: Segurança Alimentar e Nutricional (SAN). Email: khweintraub@gmail.com

${ }^{3}$ Professora Associada da Universidade Federal Rural do Rio de Janeiro. Coorientadora do trabalho pelo Programa de Pós-Graduação em Práticas em Desenvolvimento Sustentável - PPGPDS. Líder do grupo Observatório de Parcerias em Áreas Protegidas. E-mail: camila.rodrigues.ufrrj@gmail.com

${ }^{4}$ Professora Titular. Universidade Federal Rural do Rio de Janeiro - UFRRJ. Orientadora do trabalho pelo Programa de Pós-Graduação em Práticas em Desenvolvimento Sustentável - PPGPDS. Líder do Grupo de Pesquisa do CNPq: Segurança Alimentar e Nutricional (SAN). Email: ktabai@ufrrj.br
} 


\section{Introdução}

A segurança alimentar está na vanguarda dos debates e estratégias de desenvolvimento global, já que o mundo está sendo provocado pela pergunta: como vamos alimentar uma população crescente que deve chegar a 10 bilhões de pessoas antes de 2050? As taxas mundiais de fome começaram a aumentar novamente em 2014, com mais de 821 milhões de pessoas subnutridas e mais de um bilhão com deficiências de micronutrientes (FABLE CONSORTIUM, 2019). Paradoxalmente, as taxas de obesidade dispararam com quase um terço da população mundial obesa ou com sobrepeso.

Além de questões nutricionais e de distribuição, o modelo predominante de produção de alimentos tem ocasionado diferentes impactos nos ecossistemas. Os sistemas alimentares representam $24 \%$ das emissões globais de gases de efeito estufa e utilizam cerca de $70 \%$ da água doce do planeta, além de terem impactado na perda da biodiversidade terrestre global em cerca de $60 \%$. A agricultura industrial foi responsável por $80 \%$ do desmatamento em países tropicais entre 2000 e 2010 (GLOBAL FOREST ATLAS, 2019), e diante deste cenário, a Organização das Nações Unidas (ONU) declarou 2021-2030 a "Década de Restauração do Ecossistema", indicando a regeneração de 350 milhões de hectares (uma área do tamanho da Índia) até 2030 (CCAFS, 2015).

O Brasil enfrenta a insegurança alimentar ${ }^{5}$ apesar de ser o terceiro maior produtor de alimentos do mundo. Essa produção, ao invés de promover uma alimentação saudável para toda a sua população, gera destruição de ecossistemas através de um modelo predatório do agronegócio. O Brasil ocupa uma posição de destaque na conservação de florestas, uma vez que abriga 13\% das florestas do mundo (FAO, 2020). Contudo, as áreas protegidas estão ameaçadas pela indústria de alimentos, sendo que a conversão de habitats naturais em sistemas agrícolas é a maior causa de perda de biodiversidade no Brasil (BPBES, 2017).

Segurança alimentar e conservação dos ecossistemas são dois dos maiores desafios que o mundo - e o Brasil - enfrentam. Porém, esses campos de conhecimento e atuação política são muitas vezes colocados como conflituosos - parece que temos que "escolher entre fome e destruição do meio ambiente" (MALUF, 2007, p.135). Este conflito se manifesta nas políticas

\footnotetext{
${ }^{5}$ A insegurança alimentar é quando as pessoas não têm acesso regular e permanente a alimentos de qualidade e em quantidade suficiente, e sofrem algum tipo de restrição alimentar, ou seja, quando passa a comprometer alguma refeição no dia, podendo ser leve a grave, de acordo com a escala de insegurança alimentar, conforme descrevem KEPPLE e SEGALL (2011), dependerá da privação alimentar que o indivíduo está sujeito.
} 
públicas do Brasil, onde apesar dos avanços que vêm ocorrendo nas duas áreas, as iniciativas permanecem, na prática, muitas vezes separadas. Este artigo toma como pressuposto que a implementação efetiva destas políticas depende de uma atuação intersetorial ${ }^{6}$, dentro e entre as esferas de segurança alimentar e conservação dos ecossistemas. Tal visão de integração é evidente nas recomendações e metas na agenda global, promovida por instituições internacionais referentes nos dois campos.

Com o objetivo de contribuir para o desenvolvimento de soluções que permitam esta atuação intersetorial no Brasil, e especificamente no bioma da Mata Atlântica, este artigo busca refletir sobre esta interface através de um levantamento e da análise das principais políticas e programas nacionais de SAN e conservação dos ecossistemas. Além de apresentar a legislação e os programas mais relevantes e seus desafios para melhor implementação, será analisado o nível de integração entre as esferas, destacando os pontos de convergência e as lacunas entre as políticas de SAN e de conservação dos ecossistemas.

\section{A interface entre políticas de Segurança Alimentar e Nutricional (SAN) e de Conservação dos Ecossistemas: uma perspectiva global e um olhar para agricultura familiar}

No mundo todo, 815 milhões de pessoas passam fome todos os dias. Esse número pode ser reduzido, beneficiando milhões de pessoas, por meio da adoção e implementação mais amplas do manejo florestal sustentável como um componente-chave do manejo integrado da paisagem, resultando em melhores serviços ecossistêmicos protegidos, produção sustentável de alimentos e maior segurança e nutrição alimentar para todos (FAO, 2017, p. 1).

Diante do grande desafio de alimentar a população mundial, os formuladores de políticas públicas ao redor do mundo estão assumindo o compromisso de desenvolver e implementar ações que respondam a este cenário. Exemplo disto é a Agenda 2030, coordenada pela Organização das Nações Unidas (ONU) que, com o Objetivo de Desenvolvimento Sustentável - ODS 2, visa: “acabar com a fome, alcançar a segurança alimentar e melhoria da nutrição e promover a agricultura sustentável" (ONU, 2015). Com base em estimativas, muitos especialistas esperam que a produção de alimentos precise aumentar entre $25-100 \%$ até 2050 para atender às demandas

\footnotetext{
${ }^{6}$ Entende-se por intersetorialidade, a possibilidade de síntese de políticas, e esta por sua vez está no reconhecimento dos limites de poder e de atuação dos setores, pessoas e instituições. A questão fundamental da intersetorialidade é a ruptura das barreiras de comunicação, que impedem o diálogo entre diferentes setores. A ação intersetorial não elimina a importância da existência de espaços específicos de gestão de políticas setoriais e a adoção da intersetorialidade tende a favorecer políticas e ações que sejam influenciadas pela dinâmica de outros setores. A intersetorialidade surge como uma estratégia alternativa de gestão social, embora a implementação exige a superação de grandes desafios (TABAI, 2018).
} 
globais (MULHOLEM, 2017). No entanto, a maneira como ocorre esse aumento de produção afetará profundamente a saúde das pessoas e o planeta. Embora o aumento da produção de alimentos visto nas últimas décadas tenha sido devido aos avanços na agricultura convencional, há um consenso crescente, mesmo entre os agentes tradicionais, de que buscar estratégias baseadas apenas na maximização da eficiência não eliminará a fome global, continuará a resultar em dietas desequilibradas com diversidade nutricional insuficiente, a expor populações vulneráveis e pequenos agricultores a preços imprevisíveis de alimentos e causar consequências ecológicas de longo prazo (VIRA et al., 2015).

Há bastante evidência de que as florestas e os chamados tree-based systems (sistemas baseados em árvores) têm o potencial de desempenhar um papel importante na complementação da produção agrícola e no fornecimento de SAN por meio do aumento da produtividade e da sustentabilidade de longo prazo (BANEGAS, 2015). Esta integração de florestas na política de SAN está ganhando força, como visto em reuniões globais como a Conferência Internacional da FAO sobre Florestas para Segurança Alimentar em 2013, cujas recomendações de políticas afirmam que incorporar as florestas à estratégia de segurança alimentar é essencial para fortalecer seus quatro pilares - acesso, disponibilidade, uso e estabilidade (FAO, 2013). Florestas já contribuem direta ou indiretamente para a subsistência de mais de um bilhão de pessoas, mas seu papel é subestimado e subutilizado no planejamento da segurança alimentar (SUNDERLAND et al., 2013). Essa desvalorização está resultando em uma perda extrema de ecossistemas e biodiversidade em todo o planeta. Em regiões tropicais ao redor do mundo, incluindo o Brasil, a necessidade de priorizar o papel das florestas na produção de alimentos é urgente, pois "a alarmante expansão dos sistemas de produção industrial em grande escala... ameaça as contribuições das florestas ... para a segurança alimentar" quando tais ecossistemas são ativamente destruídos (SUNDERLAND et al. 2013, p. 6). De acordo com a Plataforma Brasileira de Biodiversidade e Serviços Ecossistêmicos, a conversão de habitats naturais em sistemas agrícolas é a maior causa de perda de biodiversidade no Brasil. O Brasil também é o país com a maior área afetada pelo desmatamento no mundo (BPBES, 2017). As soluções que integram as árvores à produção de alimentos são essenciais para que a nação evite uma maior degradação do ecossistema.

Além disso, muitos pequenos proprietários ou agricultores familiares - que desempenham um papel fundamental na produção de alimentos em todo o mundo - são afetados negativamente pela agricultura convencional e têm muito a ganhar com os sistemas de produção integrados com florestas. De acordo com a FAO, em 2014, havia 570 milhões de fazendas no mundo, com mais de $90 \%$ sendo administradas por um indivíduo ou núcleo familiar, ocupando 70-80\% das terras 
agrícolas do mundo (FAO, 2014). As propriedades com menos de 1 hectare representam $72 \%$ de todas as propriedades. As pequenas e médias propriedades agrícolas familiares em países de baixa e média renda têm o potencial de contribuir significativamente para a segurança alimentar global, mas produtividade do trabalho, acesso aos mercados e inovações são necessários (FAO, 2014). Os pequenos agricultores têm o potencial de conservar a biodiversidade ou deteriorá-la, dependendo dos métodos e incentivos colocados em prática. A proteção de florestas em pequenas propriedades pode contribuir para a conservação da biodiversidade em grande escala; no entanto, ainda há uma grande diferença entre esse consenso científico e a prática real de tais medidas. Os incentivos de mercado para produtos de base florestal de produção sustentável ainda são mínimos. O atual contexto de economia política dos sistemas agroalimentares é controlado por grandes corporações, no qual os pequenos agricultores que produzem safras de commodities são dependentes desse modelo de demanda e precificação, inibindo sua autonomia para escolher como e o que produzem (IPES-Food, 2017). Alguns pesquisadores sugerem que focar no fortalecimento de métodos de produção sustentáveis para alimentos de nicho, mercados domésticos e/ou "safras negligenciadas", com alto valor de mercado, poderia ser mais eficaz para os pequenos agricultores ao invés vez de tentar mudar os métodos de produção de alimentos básicos - dado que os pequenos proprietários podem nunca ser capazes de competir nesses tipos de mercado usando métodos agroecológicos (SHILOMBOLENI et al., 2019). As empresas que vendem esses produtos de nicho e apoiam seus pequenos fornecedores agrícolas serão necessárias para fornecer tais incentivos.

De acordo com o Centro Internacional de Pesquisa Florestal, entender como as florestas contribuem para um futuro com segurança alimentar é essencial para "construir sinergias e minimizar os trade-offs entre a conservação da biodiversidade e a agricultura sustentável" para alimentar 10 bilhões de pessoas até 2050 (SUNDERLAND et al. 2013, p. 6). Uma maneira de entender o importante papel que as florestas podem desempenhar nas estratégias de segurança alimentar é examinar os serviços ecossistêmicos que elas fornecem para os sistemas de produção de alimentos. Os serviços ecossistêmicos são os benefícios que a natureza proporciona às pessoas (FERRAZ et al., 2019). Essencialmente, os serviços ecossistêmicos contribuem para a segurança alimentar em três grupos principais: (1) processos ecossistêmicos que tornam possível a produção estável de alimentos; (2) diversidade e densidade nutricional e (3) adaptação e mitigação às mudanças climáticas.

No contex to da produtividade agrícola, as florestas fornecem processos ecossistêmicos que são essenciais para uma produção agrícola estável. Fertilidade do solo, dispersão de sementes, saúde de bacias hidrográficas, polinização, ciclagem de nutrientes e controle natural de pragas e doenças são alguns dos serviços ecossistêmicos mais reconhecidos fornecidos pelas árvores. A 
polinização é um serviço especialmente importante, já que muitas safras, frutas e vegetais de importância mundial dependem da polinização de insetos e animais; e tais polinizadores dependem de florestas e sistemas baseados em árvores na região (VIRA et al., 2015). A remoção de árvores e florestas em todos os ecossistemas do mundo resultou na desertificação e degradação do solo, o que diminui o rendimento das safras e prejudica a qualidade dos alimentos produzidos. A regulação natural de doenças que os insetos e outros animais podem proporcionar foi interrompida pela degradação do ecossistema e o uso de pesticidas, resultando em uma dependência crescente dos agricultores desses produtos químicos que são prejudiciais à saúde dos agricultores e ao solo, além de serem dispendiosos. As florestas também fornecem insumos agrícolas essenciais para famílias agrícolas, como material orgânico e espécies fixadoras de nitrogênio; portanto, a diminuição na qualidade e quantidade de florestas resultam nos agricultores tendo que comprar esses insumos em outro lugar e suas margens de lucro são prejudicadas (FAO, 2013). Além disso, as plantas selvagens que crescem em florestas naturais também fornecem material genético crucial para o melhoramento e inovação de culturas futuras (SUNDERLAND et al., 2013).

Outro serviço ecossistêmico essencial que as florestas fornecem são as próprias fontes de alimentos que crescem naturalmente dentro e entre as árvores, que geralmente são densas e diversificadas em nutrientes, tornando-as críticas para superar as deficiências de micronutrientes que as populações ao redor do mundo enfrentam. Mais adiante neste artigo, essas deficiências de micronutrientes serão discutidas com mais detalhes, mostrando como elas podem existir tanto em pessoas com peso abaixo da média quanto aquelas com sobrepeso. Os alimentos que crescem nas árvores e nas florestas costumam ser muito mais ricos em nutrientes essenciais do que diversos alimentos básicos, geralmente priorizados na agricultura convencional. Os cientistas estão chamando essas raízes, frutos, sementes e folhas de "colheita oculta" e estão observando as evidências científicas crescentes de que esses alimentos podem contribuir para a diversidade e qualidade de uma dieta (VIRA et al., 2015, p. 8).

Os serviços ecossistêmicos em sistemas de produção de alimentos também protegem os agricultores e consumidores dos impactos negativos das mudanças climáticas e contribuem para mitigar os impactos futuros. Os pequenos agricultores estão entre os grupos mais vulneráveis aos efeitos das mudanças climáticas; "sua baixa capacidade de reagir às mudanças, dependência de safras pluviais e localização em áreas marginais (como encostas, desertos e planícies aluviais)" tornam os agricultores muito sensíveis aos eventos climáticos extremos que estão aumentando em frequência com as mudanças climáticas (DONATTI et al., 2018. p. 1) E, a conservação de florestas pode reduzir o impacto de tais eventos na produção agrícola. Árvores e florestas reduzem a erosão do solo resultante de chuvas fortes, armazenam água no solo para disponibilidade durante as secas 
e podem criar microclimas que diminuem temperaturas locais e aumento da precipitação durante as ondas de calor (CALMON; FELTRAN-BARBIERI, 2019). Além disso, as florestas também contribuem para o que é considerado a "função de rede de segurança" em que os residentes rurais de baixa renda podem depender mais de alimentos silvestres durante escassas alimentares cíclicas ou sazonais causadas por secas ou outros motivos para baixa produção agrícola (SUNDERLAND et al., 2013, p. 5). Essas lacunas aumentam de frequência com as mudanças climáticas, portanto os alimentos advindos das florestas são ainda mais essenciais para a segurança alimentar nessas épocas. As árvores e as florestas desempenham um papel crítico na mitigação das mudanças climáticas e, portanto, na prevenção de impactos mais nocivos aos agricultores no futuro. Os cientistas estão descobrindo cada vez mais que a alta capacidade das árvores de sequestro de carbono as tornam uma das soluções mais potentes para as mudanças climáticas. Essa potência de absorção de carbono por meio do plantio de árvores e da conservação de florestas significa que os pequenos agricultores podem desempenhar um papel crucial na mitigação das mudanças climáticas (bem como nas questões relacionadas à segurança alimentar) se estratégias adequadas de integração de árvores forem implementadas.

Está se tornando cada vez mais claro em todo o mundo, especialmente nas regiões tropicais, que a segurança alimentar está intrinsecamente ligada à saúde dos ecossistemas nos quais nossos alimentos são produzidos. As políticas de segurança alimentar que não levam em consideração o valor dos serviços ecossistêmicos que as árvores e florestas fornecem, provavelmente não conseguirão atingir as metas de erradicação da fome. Da mesma forma, as políticas de conservação que não reconhecem a necessidade de incorporar a produção de alimentos e a promoção de benefícios econômicos para os agricultores na regeneração florestal também não terão sucesso. Soluções que integram árvores com produção de alimentos podem contribuir não somente para o Objetivo do Desenvolvimento Sustentável - ODS 2 - reduzindo fome, garantindo sistemas sustentáveis de agricultura, e gerando renda para pequenos agricultores - mas também para o ODS 15 (Vida Terrestre) e ODS 13 (Ação Contra a Mudança Global do Clima) (ONU, 2015).

Muitas organizações de desenvolvimento global estão reconhecendo essa necessidade de integração e a promovendo de forma mais ampla por meio de recomendações de políticas aos governos nacionais. Por exemplo, a FAO recomenda o seguinte aos governos: (1) reconhecer e integrar como contribuições de florestas a segurança alimentar e nutrição em políticas florestais; (2) desenvolver mecanismos de coordenação em toda a agricultura, silvicultura, pecuária, pesca, energia, mineração e outros setores relevantes para garantir maior coerência de segurança alimentar e funções de nutrição e melhor alinhamento de políticas; e (3) promover políticas que 
aumentam acesso a agricultores familiares a crédito, tecnologia, seguro e mercados para suas florestas e produtos da floresta (FAO, 2013).

Para que essa visão de integração aconteça em escala global, será essencial que os formuladores de políticas públicas locais, tanto de segurança alimentar quanto de conservação florestal, entendam a interconexão dos setores, reconhecendo que o cumprimento de metas em uma área não pode acontecer sem a outra, especialmente em um país de florestas tropicais como o Brasil. Além disso, os formuladores de políticas públicas devem colocar em prática projetos intersetoriais que dialoguem e reúnam profissionais de ambas áreas de atuação. Os próximos temas abordados neste artigo exploram as políticas atuais no Brasil, primeiro em relação à segurança alimentar e nutricional e em seguida em relação à conservação dos ecossistemas, analisando a interface existente e as interações entre elas.

\section{(In) Segurança Alimentar e Nutricional (SAN) - o conceito e as políticas públicas no Brasil}

Esta abordagem traz uma reflexão sobre algumas políticas públicas intersetoriais no campo de Segurança Alimentar e Nutricional (SAN) no Brasil. Destacou-se o nível de interação entre estas políticas de SAN com as políticas de conservação dos ecossistemas, investigando até que ponto eles dialogam e até onde os valores de sustentabilidade ambiental são incluídos como fundamentais para implementação dos objetivos de SAN.

O mundo está enfrentando uma crise paradoxal no campo da SAN com os aumentos simultâneos de fome e de obesidade. Depois de 14 anos de diminuição do nível de fome mundial, o mesmo voltou a subir novamente em 2015. Em 2017, 821 milhões de pessoas enfrentaram privação crônica de alimentação e mais de um bilhão de pessoas sofrem de deficiências de micronutrientes (FAO, 2019; FABLE CONSORTIUM, 2019). Ao mesmo tempo, um terço da população mundial é obesa ou com excesso de peso (FAO, 2019).

A diminuição da fome e o aumento da obesidade - chamada de transição nutricionaltambém é evidente no Brasil. O país saiu do "Mapa de Fome" em 2014, quando a taxa de subalimentação da população passou a estar abaixo de 5\% (FAO, 2014), após 13 anos seguidos de queda. Esta diminuição está relacionada com a grande diminuição de pobreza extrema que ocorreu entre 2004 e 2014, quando 28.6 milhões de pessoas, segundo o Banco Mundial, saíram da pobreza (TRIELLI et al., 2017). Também, segundo Tabai (2017), uma integração das ações políticas para segurança alimentar e para diminuição de pobreza contribuíram para a queda de fome no país. Entretanto, o Brasil encontra-se em risco de voltar para o "Mapa da Fome" devido a recessão econômica que colocou entre 2.5 e 3.6 milhões de pessoas abaixo da linha de pobreza desde 2015 
(TRIELLI et al., 2017). Segundo o pesquisador Menezes, membro de ActionAid e IBASE, a conexão entre pobreza e fome é intrínseca e os resultados até agora evidenciam que o número de pessoas que passam fome está subindo de novo (DOMENICI, 2018).

No contexto atual, em virtude da pandemia de COVID-19 que se espalhou pelos países em 2020, a situação está ainda mais grave, com consequências no aumento das desigualdades sociais. Segundo um relatório da ONU de junho de 2020, a pandemia poderia colocar 49 milhões de pessoas em situação de pobreza extrema antes do final do ano e o número de pessoas enfrentando insegurança alimentar em caráter emergencial poderia quase dobrar de 135 milhões para 265 milhões de pessoas (ONU, 2020). Cadeias de fornecimento de alimentos estão sendo interrompidas pelas restrições de trânsito, impactando ambos os consumidores e produtores, assim como a disponibilidade de alimentos. A diminuição de renda e o aumento de desemprego que acompanham a crise econômica estão deixando a população mais vulnerável e em maior risco de insegurança alimentar, tendo em vista que quase metade das rendas da população de baixo poder aquisitivo é direcionada à alimentação (ONU, 2020). Estes impactos da pandemia e da crise econômica estão evidentes no Brasil, um dos países com maior número de casos de COVID-19 do mundo, onde a população já enfrenta situações precárias de saneamento, saúde, e acesso aos alimentos. Como Maluf declara:

Era previsível que o alimento, tanto sua disponibilidade como o acesso a ele, viesse a ocupar o centro das preocupações e urgências no contexto de pandemia pelo qual estamos passando, ao lado, e como complemento indispensável, dos cuidados com a saúde das pessoas infectadas ou não pelo vírus mais recente (MALUF, 2020, p. 1).

Insegurança alimentar é mais que a impossibilidade de acesso à calorias suficientes; também tem a ver com a qualidade nutricional dos alimentos consumidos. O Brasil, assim como o mundo em geral, está enfrentando uma outra crise de má nutrição e insegurança alimentar: a obesidade. Segundo FAO (2019), 38.9\% de adultos no mundo estão com sobrepeso, e entre 2000 e 2016 a prevalência de obesidade em crianças e adolescentes dobrou. Um aumento na industrialização e no processamento de alimentos, combinados com a urbanização e o crescimento econômico da população, têm contribuído para este aumento drástico de obesidade na última década. A dieta não saudável é agora o principal fator de risco para mortes em todo o mundo (FAO, 2019) O Brasil é um exemplo deste aumento de obesidade, com quase $20 \%$ da população obesa, e mais de 50\% acima do peso (VALENTE, 2018). A dieta brasileira, originalmente composta por alimentos naturais e integrais como arroz, feijão e saladas, passou a ser uma dieta de ultraprocessados baratos e de pouco valor nutricional. Já em 2009, a Pesquisa de Orçamento Familiar mostrou que a porcentagem de despesas no orçamento de famílias com alimentação fora 
de casa subiu de 24,1\% a 31,1\% entre 2002/03 e 2008/2009 (IBGE, 2018). O mercado de "fast food" cresceu 82\% entre 2008 e 2013. O mercado de alimentos no Brasil é dominado por alimentos industrializados e o impacto deles na saúde da população é evidente (MINTEL, 2013).

O governo brasileiro tem criado várias políticas públicas para lidar com estes desafios de segurança alimentar. Contudo, para entender melhor os objetivos destas políticas e os desafios que enfrentam, pretende-se estabelecer uma compreensão de segurança alimentar como um conceito inclusivo, que inclui soberania alimentar e uma cadeia de produção e consumo sustentável. Vale destacar que as políticas públicas brasileiras já preveem uma interlocução em nível teórico entre este conceito de segurança alimentar e a conservação da natureza.

A Segurança Alimentar e Nutricional (SAN) é o direito de todos ao acesso regular e permanente a alimentos de qualidade, em quantidade suficiente, sem comprometer o acesso a outras necessidades essenciais (BRASIL, 2006a). Esta definição, utilizada nas políticas brasileiras do SAN, incorpora os princípios estabelecidos pela Food and Agriculture Organization - FAO e aqueles oriundos do Direito Humano à Alimentação Adequada (DHAA). O DHHA foi estabelecido no Pacto Internacional de Derechos Economicos, Sociales y Culturales (PIDESC), aprovado em 1966.

O conceito de SAN no Brasil vai além da questão de direito humano, pois também considera a soberania e a sustentabilidade ambiental, econômica e social (TABAI, 2018). A soberania alimentar está relacionada com o direito de todos os indivíduos, comunidades, povos e países a decidir e definir suas próprias políticas de agricultura e alimentação. Na prática, isso significa que os povos devem decidir o que cultivar, como é o que comercializar, e controlar os recursos naturais básicos (CIDAC, 2019). Soberania alimentar é um princípio que qualifica o SAN, um objetivo de ações e políticas públicas (MALUF, 2007). Assim, a sustentabilidade ambiental, econômica e social está relacionada diretamente com a produção dos alimentos. Uma produção que deteriora os ecossistemas e não promove o bem-estar dos agricultores não contribui para segurança alimentar, segundo o conceito de SAN nas políticas públicas brasileiras (BRASIL, 2014).

Este conceito mais inclusivo de SAN está presente na Lei Orgânica de Segurança Alimentar e Nutricional (LOSAN), $n^{\circ} 11.346$, sancionada em 2006, regulamentada no Brasil pelo Decreto $\mathrm{n}^{\circ} 7272$ de 2010, que instituiu a política referencial de SAN na qual o governo federal garante o DHAA para a população brasileira (BRASIL, 2006.). A LOSAN definiu os marcos legais e institucionais para a agenda de SAN e "abriu a possibilidade de cobranças do reconhecimento da importância de tratar de temas como o DHAA e a soberania alimentar" (NEVES, 2018). A Lei inclui a criação do Sistema Nacional de Segurança Alimentar e Nutricional (SISAN), a recriação 
do Conselho Nacional de Segurança Alimentar e Nutricional (CONSEA), e a elaboração do Plano Nacional de Segurança Alimentar e Nutricional (PLANSAN 2012/2015). Em 2019, o CONSEA foi lamentavelmente suspenso por meio da Medida Provisória 870/2019 (CONTRAF BRASIL, 2019).

O texto da LOSAN inclui várias referências à conservação do meio ambiente como parte do conceito de segurança alimentar. O Artigo $3^{\circ}$ afirma que a SAN deve ter como base "práticas alimentares promotoras de saúde que respeitem a diversidade cultural e que sejam ambiental, cultural, econômica e socialmente sustentáveis" (BRASIL, 2006.) Já o Artigo 4o afirma que a SAN abrange "a conservação da biodiversidade e a utilização sustentável dos recursos" (BRASIL, 2006). Em 2010, a Política Nacional de Segurança Alimentar e Nutricional (PNSAN) foi criada para regulamentar a LOSAN e visou integrar as políticas e programas setoriais (NEVES, 2018; BRASIL, 2010). A sustentabilidade na produção de alimentos ficou mais explícita com a diretriz do PNSAN, visando a "promoção do abastecimento e estruturação de sistemas sustentáveis e descentralizados, de base agroecológica, de produção, extração, processamento e distribuição de alimentos" e o seu objetivo de "promover sistemas sustentáveis de base agroecológica, de produção e distribuição de alimentos que respeitem a biodiversidade e fortaleçam a agricultura familiar" (BRASIL, 2010).

Este conceito mais abrangente de Segurança Alimentar e Nutricional também é evidente no conceito de alimentação saudável que é utilizado no Guia Alimentar para a População Brasileira (BRASIL, 2014). O conceito aborda "a relação entre alimentação e saúde, levando em conta nutrientes, alimentos, combinações de alimentos, refeições e dimensões culturais e sociais das práticas alimentares" (BRASIL, 2018, p. 12). Alimentação saudável se baseia no consumo e preparação culinária principalmente de alimentos in natura ou minimamente processados, com variedade e predominantemente de origem vegetal. O guia também enfatiza a utilização de alimentos produzidos pela agricultura familiar, de preferência orgânicos ou de base agroecológica.

\section{Políticas Intersetoriais de SAN para promoção da agricultura familiar}

A agricultura familiar é reconhecida como fundamental para SAN no Brasil, ambos em termos de subsistência dos agricultores em si e para o consumo da população geral do país. Os dados de 2014 da Embrapa mostram que 4.3 milhões de unidades produtivas agrícolas são de pequenos produtores, englobando $84 \%$ do total e providenciando 14 milhões de empregos no país (EMBRAPA, 2014). Agricultura familiar respondia em 2016 por uma grande porção de várias produções nacionais: $87 \%$ de mandioca, $70 \%$ de feijão, $58 \%$ de leite, e $50 \%$ do plantel de aves (FUNDAÇÃO CARGILL, 2016). Contudo, olhando para a produção de culturas como soja e trigo, 
a agricultura familiar tem uma participação bem menor, com somente $16 \%$ e $21 \%$ respectivamente (EMBRAPA, 2014). Autoridades públicas brasileiras publicaram que $70 \%$ dos alimentos consumidos no Brasil foram produzidos por agricultura familiar - um dado frequentemente replicado em trabalhos acadêmicos. No entanto, após uma análise mais aprofundada, esse dado foi reavaliado e chegou-se à conclusão de que a percentagem real da contribuição de agricultura familiar nas despesas alimentares dos brasileiros é mais perto de 22\% (HOFFMAN, 2014). Tal dado não diminui a importância da agricultura familiar para a SAN, mas destaca a necessidade de implementação de mais políticas e programas que significativamente apoiam o pequeno agricultor a levar sua produção para a mesa dos brasileiros.

A agricultura familiar tem um alto potencial de produtividade, se comparada a outro tipo de agricultura, especialmente em cadeias de maior valor que necessitam mais intensidade em termos de força de trabalho, como, por exemplo, a produção de frutas e legumes (MMA, 2019). Adicionalmente, a agricultura familiar tem "menos potencial danoso aos recursos naturais" (MMA, 2019). Especificamente, quando os incentivos certos existem, a agricultura familiar pode funcionar como um método de conservação para nossas terras.

De acordo com IFAD/Programa das Nações Unidas para o Meio Ambiente - UNEP (2013), sendo devidamente apoiada por políticas públicas e incentivos, Agricultura familiar, a partir de sua experiência e conhecimento das condições e realidades locais, tem enorme potencial de transformar a paisagem rural e desencadear formas novas e sustentáveis de se produzir alimentos (Ministério de Meio Ambiente, 2018).

Existem vários programas e políticas intersetoriais que promovem segurança alimentar e nutricional através da valorização e fortalecimento da agricultura familiar. As políticas que apoiam a agricultura familiar acabam requerendo ações intersetoriais porque a sua implementação geralmente envolve apoio tanto do lado de produção (assistência técnica) quanto do lado de venda (acesso aos mercados). Por exemplo, a assistência técnica rural que vem do setor governamental de desenvolvimento rural, através de Empresas de Assistência Técnica e Extensão Rural (EMATER), é fundamental para qualquer programa de SAN focado no agricultor (MONTEIRO, 2019). No nível teórico, estes programas de fortalecimento do agricultor também dialogam com os setores governamentais vinculados à preservação do meio ambiente. No entanto, a integração na gestão entres estes setores na prática é mais escassa.

Entre estes programas intersetoriais de SAN, o mais amplo e antigo é o Programa Nacional de Alimentação Escolar (PNAE), que existe desde a década de 1950 e tem por objetivo oferecer alimentação saudável aos milhões de estudantes das escolas públicas de todo Brasil (NEVES, 2018). O PNAE é um programa intersetorial e gerenciado pelo Fundo Nacional de 
Desenvolvimento da Educação (FNDE), que repassa recursos financeiros aos estados e municípios parcialmente para suprir as necessidades nutricionais dos estudantes (NEVES, 2018). Contudo, em 2009, a conexão do programa com a agricultura familiar se fortaleceu quando se tornou obrigatória a aplicação mínima de $30 \%$ destes recursos para compra de alimentos de agricultura familiar local (DESANS, 2016). Existe um mecanismo, uma chamada pública que pode ser gerenciada pelo município ou estado (entidade executora), onde agricultores, associações ou cooperativas de agricultores familiares podem aplicar para que seus produtos sejam comprados para fornecer às escolas públicas. Os indivíduos e grupos formais são obrigados a possuir Declaração de Aptidão (DAP) ao Programa Nacional de Fortalecimento da Agricultura Familiar (PRONAF), que funciona como uma comprovação do seu status de agricultor familiar (BRASIL, 2009). “O PNAE é uma política pública complexa, pois, para a sua efetividade é necessária integração entre diferentes órgãos, instituições e agentes de diferentes setores e repartições. Requer uma atuação integrada, de modo intersetorial” (NEVES; TABAI, 2020, p. 88).

Outro programa que faz parte de uma política intersetorial é o Programa de Aquisição de Alimentos (PAA), criado pelo art. 19 da Lei n ${ }^{\circ}$ 10.696, de 02 de julho de 2003 (BRASIL, 2003). O PAA visa promover o acesso à alimentação e incentivar a agricultura familiar através da compra de produtos de agricultores familiares por instituições do setor público que atendem pessoas com riscos de insegurança alimentar e nutricional como hospitais, presídios, universidades e empresas públicas (MDSA, 2016). O PAA incentiva o consumo e a valorização dos produtos de agricultura familiar, promove o acesso da agricultura familiar aos mercados das compras públicas, estimula o cooperativismo e o associativismo e valoriza a biodiversidade e produção agroecológica dos alimentos (MDSA, 2016). O PAA é desenvolvido em cinco modalidades diferentes: Doação Simultânea, Compra Direta, Formação de Estoques, PAA Leite e Compra Institucional. O orçamento do PAA é composto por recursos do Ministério do Desenvolvimento Social e Combate à Fome (MDS) e do Ministério do Desenvolvimento Agrário (MDSA, 2016).

Apesar da visão integrada e intersetorial dos programas de PAA e PNAE, ambos enfrentam dificuldades para serem implementados no nível local devido à falta de pessoal capacitado e de infraestrutura dos órgãos municipais que deveriam dar suporte aos programas (NEVES, 2018). Também, as estruturas de armazenamento e conservação dos alimentos impedem a participação de agricultores familiares. Ainda, a falta de apoio administrativo para os agricultores familiares para a criação de cooperativas e inscrição na DAP também contribuem para a falta de participação de agricultores, além de outros obstáculos.

Outra política relevante é a Política Nacional de Assistência Técnica e Extensão Rural (PNATER), sendo a Empresa de Assistência Técnica e Extensão Rural do Estado do Rio de Janeiro 
(EMATER-RIO) sua principal executora no Estado. A PNATER "busca promover o desenvolvimento rural sustentável a partir de uma agricultura de base ecológica, que respeite os conhecimentos locais e fortaleça a participação social na gestão da política" através da destinação de recursos federais em ações de empresas públicas ou privadas que fornecem assistência técnica rural (BRASIL, 2010). A política visa providenciar assistência técnica acessível e gratuita para orientar a produção do agricultor e a gestão do negócio.

A criação da PNATER representou o restabelecimento da participação federal na oferta de serviço de extensão rural, começando em 2003, depois de mais de uma década de ausência. Podese considerar ainda que, por meio da PNATER, existe uma tentativa de "instituir uma mudança radical nos enfoques teóricos, filosóficos e metodológicos que fundamentam a extensão rural" (DINIZ; HESPANHOL, 2018).

Em quase todos os estados do Brasil, existe a figura da EMATER, uma empresa pública que oferece serviços de assistência técnica para agricultura familiar e está habilitada a receber financiamento do governo federal como parte do PNATER. Geralmente os técnicos vinculados às empresas de ATER (EMATER), são pagos pelos governos locais, e são geradores e difusores de conhecimento, tecnologias e serviços para apoiar os agricultores familiares com a missão de melhorar as condições de vida no campo.

As EMATER operacionalizam as políticas públicas de desenvolvimento rural para agricultores, articulando entidades relevantes e parcerias e executando programas oficiais no campo. Por exemplo, emitem a Declaração de Aptidão do PRONAF (DAP), o qual é fundamental para agricultores familiares participarem em programas previamente mencionados como PRONAF, PNAE e PAA (ICMBio, 2017).

\section{Conservação de ecossistemas - políticas públicas ambientais no Brasil}

O Brasil é um país megabiodiverso, abrigando $70 \%$ das espécies do planeta (BPBES, 2017). Com esta responsabilidade mundial de preservar seus ecossistemas, o Brasil é signatário de compromissos ambientais internacionais, como o "Acordo de Paris" sobre mudanças climáticas, a "Iniciativa $20 \times 20$ ", que trata da restauração de 20 milhões de hectares de terra na América Latina e no Caribe, e a Agenda 2030 (ONU, 2015). Neste cenário, um compromisso assumido é a restauração de 12 milhões de hectares de florestas até 2030, 1 milhão especificamente no bioma da Mata Atlântica (BENINI; ADEODATO, 2017). 
A Mata Atlântica, área que será tratada com maior ênfase neste artigo, é um dos ecossistemas mais ameaçados no mundo, com apenas $12 \%$ de sua cobertura originária ${ }^{7}$ e que continua a sofrer com práticas rurais de monocultura e expansão da mancha urbana de cidades dos estados de São Paulo e Rio de Janeiro. A Mata Atlântica é um dos 34 hotspots de biodiversidade do mundo, localizada ao longo da costa atlântica brasileira, do estado do Rio Grande do Norte ao Rio Grande do Sul e abarcando também regiões do Paraguai e Argentina (BPBES, 2017). É um bioma que continua a sofrer com práticas rurais de monocultura e expansão da mancha urbana de cidades paulistas e cariocas. Mesmo assim, a Mata Atlântica é lar de espécies de fauna e flora ameaçadas, como o mico-leão-dourado e o Pau-Brasil, e é responsável por fornecer água limpa para cerca de $70 \%$ da população brasileira (MMA, 2010).

Ao longo dos anos, o Brasil tem investido em diferentes iniciativas para a proteção da Mata Atlântica, e de seus outros biomas, através de vários mecanismos legais, políticas públicas, e programas. Contudo, o crescente corte orçamentário que afeta os órgãos ambientais em termos de infraestrutura e de pessoal, e a complexidade da gestão das terras que possuem floresta, resultam num grande déficit da implantação destas leis florestais e de conservação da natureza. Este artigo sugere que um aspecto que reforça a complexidade da gestão de terras com florestas é o fato de que muitas delas são utilizadas para produção de alimentos de maneira conflitante com a conservação dos ecossistemas. Portanto, para melhor implementar as leis de conservação, argumenta-se que tais políticas precisam incorporar de alguma forma as possibilidades de produção alimentar nestas propriedades. Uma das políticas públicas relevantes para a conservação da natureza do Brasil é o Sistema Nacional de Unidades de Conservação (SNUC), instituído pela Lei 9.985, de 18 de julho de 2000 (BRASIL, 2000). O Sistema Nacional de Unidades de Conservação (SNUC) estabelece um conjunto de diretrizes e procedimentos para criação, implementação e gestão das unidades de conservação com o objetivo de conservar a natureza do Brasil. As unidades de conservação (UC) são um tipo especial de área protegida, instituídas pelo poder público, que visam assegurar a proteção de ecossistemas do território nacional e das águas jurisdicionais, preservando o patrimônio biológico existente (BRASIL, 2000).

O SNUC é formado por 12 categorias de UC, as quais são organizadas em dois grandes grupos: unidades de proteção integral e unidades de uso sustentável (BRASIL, 2000). Unidades de proteção integral, a categoria mais restrita, só permite o uso indireto dos seus recursos naturais, por exemplo como turismo e pesquisa, com algumas exceções. Unidades de Uso Sustentável, por

\footnotetext{
${ }^{7}$ Segundo Resende et al. (2018), novos dados de remote sensing mostram uma cobertura vegetal na Mata Atlântica de $28 \%$ do original, ou 32 milhões de hectares.
} 
outro lado, permitem uso direto e exploração dos recursos naturais, porém mantendo a biodiversidade do local e os seus recursos renováveis. As UCs podem ser criadas em âmbito federal, estadual, ou municipal, e esta distinção decide qual órgão gerencia a unidade. O principal instrumento para gestão das UC é o plano de manejo, o qual traz informações sobre os atributos econômicos, sociais e naturais.

O SNUC também prevê mecanismos para a participação da sociedade na gestão dos UC através de conselhos gestores, nos quais membros do poder público, setor privado, academia, e outros setores debatem e encaminham propostas sobre a gestão das UC. A visão do SNUC vai além de só preservar a natureza, mas também de promover qualidade de vida e desenvolvimento económico para as pessoas. Segundo o Ministério do Meio Ambiente (MMA), "sob um olhar econômico e socioambiental, de acordo com o tipo de atividade econômica permitida em cada categoria, a classificação das UC pode ser analisada da seguinte maneira” (Figura 1):

Figura 1: Classificação das UCs por atividade econômica permitida

\begin{tabular}{|c|c|c|}
\hline Chase & $\begin{array}{l}\text { Principais tipes de wo, contemphados } \\
\text { na Lei no 9.985/2000 }\end{array}$ & Categeria de manejo \\
\hline $\begin{array}{l}\text { Clase } 1 \text { - Pesquia cientifica e } \\
\text { educapajo ambiental }\end{array}$ & $\begin{array}{l}\text { Deservolvimento de pesquisa cientifica } \\
\text { e de educaç ào ambiental }\end{array}$ & Rexerva biológica; estaçăo ecológica \\
\hline $\begin{array}{l}\text { Chase } 2 \text { - Pesquiga cie ntifica, educaçăo } \\
\text { ambiental e vis taçäo }\end{array}$ & Turismo em contato com a natureza & $\begin{array}{l}\text { Parques nacionais e estaduais, reserve } \\
\text { particular do patrirsónio natural }\end{array}$ \\
\hline $\begin{array}{l}\text { Clase } 3 \text { - Produgäo florestal, pesquiea } \\
\text { cientifica evisitapăo }\end{array}$ & Produräo florestal & Florestes nacionais e estaduais \\
\hline $\begin{array}{l}\text { Clase } 4 \text { - Extrativismo, pespuia } \\
\text { cientifica e visitapăo }\end{array}$ & $\begin{array}{l}\text { Extrativismo por popalsçōes } \\
\text { tradicionais }\end{array}$ & Reseervas extrativiatas \\
\hline $\begin{array}{l}\text { Clases S - Agncultura de baixo } \\
\text { impacto, pesquisa cientifica, vaitaçäo, } \\
\text { produç äo fore stal e extrativiemo }\end{array}$ & $\begin{array}{l}\text { Áreas publicas o privadar onde a } \\
\text { productäo agricola e pecuína é } \\
\text { compe thilizada com os obje trvos da } \\
\text { UC }\end{array}$ & $\begin{array}{l}\text { Reserva de deservolvimento } \\
\text { sustentivel, refugio de vida silvestre; } \\
\text { monume nto natural }\end{array}$ \\
\hline $\begin{array}{l}\text { Classe } 6 \text { - Agropecuína, atividade } \\
\text { industral, nuele populacional ubanoe } \\
\text { rual }\end{array}$ & $\begin{array}{l}\text { Temes públicas e particulates com } \\
\text { possibilidide de usos variados visando a } \\
\text { un orderamento tmitorial sustentivel }\end{array}$ & $\begin{array}{l}\text { Axea de proteça ambiental; frea do } \\
\text { relevantr interese ecologico }\end{array}$ \\
\hline
\end{tabular}

Fonte: MMA, 2018.

Analisando os objetivos do SNUC, quatro dos doze mencionam desenvolvimento econômico e/ou observam as necessidades das populações locais. Por exemplo: "valorizar econômica e socialmente a diversidade biológica" e "considerem as condições e necessidades das populações locais no desenvolvimento e adaptação de métodos e técnicas de uso sustentável dos recursos naturais" (MMA, 2018). Nenhum dos objetivos trata explicitamente de alimentação, 
segurança alimentar e nutrição. A agricultura é mencionada apenas uma vez no SNUC, em referência à categoria de UC denominada de Reserva Extrativista, na qual populações extrativistas tradicionais usam a área para agricultura de subsistência, extrativismo, e criação de animais de pequeno porte. Além disso, a segurança alimentar não é mencionada explicitamente (BRASIL, 2000).

Outra política com repercussão no projeto em questão é o novo Código Florestal, instituído pela Lei 12.651, de 25 de maio de 2012, que estabelece limites de uso de propriedades rurais para a proteção da vegetação nativa (BRASIL, 2012). Todas propriedades rurais são obrigadas a cumprir os seguintes requisitos: (1) Cumprimento do CAR (Cadastro Ambiental Rural); (2) preservação da vegetação nativa nas áreas de preservação permanente (APP); e (3) preservação de vegetação na parcela da propriedade que cumpre a percentagem requisitada da Reserva Legal (RL) para o bioma em que a propriedade está localizada. Embora a Lei tenha sido instituída em 2012, ainda falta muito para a implementação destes 3 itens do código em todas propriedades. É estimado que existe um déficit de 8 milhões de hectares de APP e 11 milhões de hectares de Reserva Legal para ser restaurado (GUIDOTTI, 2017). O Código Florestal aborda temas como sistemas agroflorestais, agricultura familiar, e alimentação. Contudo, pode-se argumentar que o Código Florestal procura mais garantir que florestas existam ao lado de iniciativas agropecuárias de grande porte e agroindústria, mais que verdadeiramente integrar produção de alimentos dentro da floresta.

Enquanto o Código Florestal se refere ao país inteiro, a Lei da Mata Atlântica (Lei 11.428, de 22 de dezembro de 2006) especifica a legislação para o bioma Mata Atlântica. Ela é a principal política que regulamenta a proteção e uso da biodiversidade e de recursos da floresta do bioma onde vivem 70\% da população brasileira (SOS MATA ATLÂNTICA, 2019). A Lei prevê doações da iniciativa privada para projetos de conservação, delimita qual é o domínio da floresta, proíbe o desmatamento de florestas primárias, e cria regras para exploração econômica. Existem especificações de como e quando a vegetação pode ser explorada para uso humano, indiretamente fazendo referência à segurança alimentar da população (SOS MATA ATLÂNTICA, 2020). Por exemplo, segundo a Lei, pequenos produtores e populações tradicionais podem cortar vegetação secundária em estágio médio de regeneração somente para o seguinte, com autorização do órgão estadual competente e o Ibama.

Também menciona no Artigo 9 que a exploração não-comercial de espécies de flora nativa para consumo dos pequenos produtores rurais e populações tradicionais não requer autorização dos órgãos competentes. Porém, o tipo de vegetação e estágio de regeneração afeta o que pode ser feito, sendo obviamente o mais restritivo para floresta primária e estágio de regeneração avançada. 
Dentre as principais políticas de conservação dos ecossistemas que foram analisadas, há uma ausência da inclusão explícita da perspectiva de SAN. Com base nas recomendações internacionais que aconselham a integração de produção alimentar em modelos de conservação de ecossistemas, este artigo sugere que esta ausência de SAN nas políticas ambientais do Brasil pode ser um fator contribuinte para a falta de integração entre as duas agendas. Assim, os aspectos identificados nas políticas ambientais citadas no artigo buscam evidenciar os possíveis pontos de interface para um debate mais aprofundado sobre a integração entre conservação de ecossistemas e segurança alimentar.

\section{Considerações finais}

As políticas públicas nacionais relevantes para o debate empreendido neste artigo foram destacadas com o objetivo de compreender as interfaces e os aspectos que podem promover a intersetorialidade entre a SAN e a conservação dos ecossistemas. Nesta análise, ficou evidente que as políticas de SAN no Brasil são mais intersetoriais e tendem a ser mais inclusivas da perspectiva ambiental que o inverso.

Existem vários programas e políticas intersetoriais de Segurança Alimentar e Nutricional que explicitamente incluem conservação de ecossistemas e sustentabilidade ambiental nos próprios objetivos das políticas. Contudo, elas enfrentam inúmeros desafios para implementação na prática devido a administração deficiente, a falta de diálogo entre departamentos governamentais, a falta de recursos, entre outras questões. Foi demonstrado que nas principais políticas de conservação dos ecossistemas existe pouca inclusão da perspectiva de SAN na teoria, e ainda menos na prática.

Ao mesmo tempo, foi apresentado uma perspectiva de integração que está tomando um lugar mais pronunciado no nível global de políticas públicas, como pode ser observado nas recomendações internacionais sobre os ODS e os planos da FAO, que utiliza o conceito de serviços ecossistêmicos para justificar esta integração, inclusive, o tema do dia mundial de alimentação da FAO de 2020 foi Sistemas Alimentares Sustentáveis. Estas recomendações utilizam o conceito de serviços ecossistêmicos para justificar esta integração, demonstrando os benefícios essenciais que a natureza providencia para o bem-estar humano. Sugere-se que sejam prioridades governamentais no Brasil a promoção de políticas públicas intersetoriais que incorporem esta visão integradora para atingir suas metas internacionais de sustentabilidade. 


\section{Referências}

BANEGAS, D. Forests Can Play a Key Role in Addressing Global Hunger and Malnutrition. US FOREST SERVICE/USDA: 2015. Disponível em: https://www.fs.usda.gov/features/forestscan-play-key-role-addressing-global-hunger-and-malnutrition. Acesso em: 15 jan. 2020.

BENINI, R; ADEODATO, S. Forest Restoration Economy. São Paulo: The Nature Conservancy Brasil - TNC Brasil. Ed. Sérgio Adeodato, 2017, 136p.

BPBES. Diagnóstico Brasileiro sobre Biodiversidade e Serviços Ecossistêmicos. SPBC: 2017. Disponível em: https://www.bpbes.net.br/wp-content/uploads/2018/08/Dialogos_BPBES.pdf. Acesso em: 25 jan. 2020.

BRASIL. Presidência da República. Casa Civil. Lei ${ }^{\circ}$ 12.651, de 25 de maio de 2012. Dispõe sobre a proteção da vegetação nativa; altera as Leis $n^{\circ}$ s 6.938, de 31 de agosto de 1981, 9.393, de 19 de dezembro de 1996, e 11.428, de 22 de dezembro de 2006; revoga as Leis $\mathrm{n}^{\circ}$ s 4.771, de 15 de setembro de 1965, e 7.754, de 14 de abril de 1989, e a Medida Provisória n ${ }^{\circ}$ 2.166-67, de 24 de agosto de 2001; e dá outras providências. Brasília, DF: Presidencia da Republica 2012. Disponível em: http://www.planalto.gov.br/ccivil_03/_Ato2011-2014/2012/Lei/L12651.htm. Acesso em: 15 out. 2018.

BRASIL. Presidência da República. Casa Civil. Lei n ${ }^{\circ}$ 11.346, de 15 de setembro de 2006. Cria o Sistema Nacional de Segurança Alimentar e Nutricional - SISAN com vistas em assegurar o direito humano à alimentação adequada e dá outras providências. Brasília, DF: Presidência da Republica, 2006. Disponível em: http://www.planalto.gov.br/ccivil_03/_ato20042006/2006/lei/111346.htm. Acesso em: 12 out. 2018.

BRASIL. Ministério da Saúde. Secretaria de Atenção à Saúde. Departamento de Atenção Básica. Guia alimentar para a população brasileira / Ministério da Saúde, Secretaria de Atenção à Saúde, Departamento de Atenção Básica. - 2. ed. - Brasília: Ministério da Saúde, 2014.

BRASIL. Ministério de Desenvolvimento Social. Compras Institucionais para promoção da Alimentação Adequada e Saudável: As contribuições do Programa de Aquisição de Alimentos. Brasília, DF, 2018.

BRASIL. Lei $\mathbf{n}^{\mathbf{0}}$ 9.985, de 18 de julho de 2000. Regulamenta o art. 225, $\S 1^{\circ}$, incisos I, II, III e VII da Constituição Federal, institui o Sistema Nacional de Unidades de Conservação da Natureza e dá outras providências. Brasília: Presidência da República, 2000. Disponível em: http://www.planalto.gov.br/ccivil_03/leis/19985.htm. Acesso em: 3 ago. 2018

BRASIL. Presidência da República. Casa Civil. Decreto n 9.064, de 31 de maio de 2017. Dispõe sobre a Unidade Familiar de Produção Agrária, institui o Cadastro Nacional da Agricultura Familiar e regulamenta a Lei $\mathrm{n}^{\circ} 11.326$, de 24 de julho de 2006 , que estabelece as diretrizes para a formulação da Política Nacional da Agricultura Familiar e empreendimentos familiares rurais. Brasília, DF, 2017. Disponível em: http://www.planalto.gov.br/ccivil_03/_ato20152018/2017/decreto/D9064.htm. Acesso em: 5 de junho 2020.

BRASIL. Presidência da República. Casa Civil. Lei $\mathbf{n}^{\circ}$ 10.696, de 2 de Julho de 2003. Dispõe sobre a repactuação e o alongamento de dívidas oriundas de operações de crédito rural, e dá outras providências. Brasília: Presidência da República, 2003. Disponível em: http://www.planalto.gov.br/ccivil_03/LEIS/2003/L10.696.htm. Acesso em: 3 ago. 2018. 
BRASIL. Casa Civil. Decreto $\mathbf{n}^{\circ}$ 7.272, de 25 de agosto de 2010. Regulamenta a Lei $\mathrm{n}^{\circ} 11.346$, de 15 de setembro de 2006, que cria o Sistema Nacional de Segurança Alimentar e Nutricional SISAN com vistas a assegurar o direito humano à alimentação adequada, institui a Política Nacional de Segurança Alimentar e Nutricional - PNSAN, estabelece os parâmetros para a elaboração do Plano Nacional de Segurança Alimentar e Nutricional, e dá outras providências. Disponível em: http://www.planalto.gov.br/ccivil_03/ato20072010/2010/decret o/d7272.htm. Acesso em: 18 fev. 2019.

CALMON, M; FEITRON-BARBIERI, R. 4 Ways Farmers Can Adapt to Climate Change and Generate Income. WRI, 2019. Disponível em: https://www.wri.org/blog/2019/12/4-waysfarmers-can-adapt-climate-change-and-generate-income. Acesso em: 28 jan. 2020.

CCAFS. Climate Change, Agriculture, and Food Security. Food Emissions. [ca. 2015]. Disponível em: https://ccafs.cgiar.org/bigfacts/\#theme=food-emissions. Acesso em: 3 jul. 2019

CIDAC. Centro de Intervenção para o Desenvolvimento Amílcar Cabral. O que fazemos. 2019. Disponivel em: https://www.cidac.pt/index.php/o-que-fazemos/. Acesso em 10 jul. 2019.

DESANS. Departamento de Segurança Alimentar e Nutricional Sustentável. Primeiro Plano Municipal de Segurança Alimentar e Nutricional de Duque de Caxias. 2016. Disponível em: http://www.mds.gov.br/webarquivos/arquivo/seguranca_alimentar/caisan/Publicacao/Caisan_Mu nicipal/1_Duque_de_Caxias_2016_RJ.pdf Acesso em: 15 ago. 2019.

DINIZ, R; HESPANHOL, A. Reestruturação, reorientação e renovação do serviço extensionista no Brasil: a (difícil) implementação da política nacional de assistência técnica e extensão rural (PNATER). Extensão Rural, DEAER - CCR - UFSM, Santa Maria, v.25, n.2, p.7-30, 2018.

DOMENICI, T. Hunger Crisis Returning to Brazil, says Francisco Menezes. Brasil Wire, 2018. Disponível em: http://www.brasilwire.com/hunger-crisis-returning-to-brazil-says-franciscomenezes/. Acesso em: 3 jul. 2019.

DONATTI, C. HARVEY, C; MARTINEZ-RODRIGUEZ, M; VIGNOLA, R. Vulnerability of smallholder farmers to climate change in Central America and Mexico: current knowledge and research gaps. Climate and Development, 2018. Disponível em: https://www.researchgate.net/publication/323542859_Vulnerability_of_smallholder_farmers_to_ climate_change_in_Central_America_and_Mexico_current_knowledge_and_research_gaps Acesso em: 8 jul. 2019.

EMBRAPA. Agricultura Familiar no Brasil. 2014. Disponível em: https://www.embrapa.br/en/aiaf-14-agricultura-familiar-no-brasil. Acesso em: 3 de junho 2020.

FABLE CONSORTIUM. Pathways to Sustainable Land-Use and Food Systems. Executive summary of the 2019 Report. Laxenburg, Paris: International Institute for Applied Systems Analysis, Sustainable Development Solutions Network, 2019. Disponível em: http://unsdsn.org/wp-content/uploads/2019/07/2019-FABLE-Report_Executive-Summary_HighResolution.pdf Acesso em: 3 ago. 2019.

FAO. Joint Statement on COVID-19 Impacts on Food Security and Nutrition. Rome, 2020. Disponível em: http://www.fao.org/news/story/en/item/1272058/icode/. Acesso em: 15 jun. 2020. 
.The state of food security and nutrition in the world. Roma: FAO, 2019. Disponível em: http://www.fao.org/state-of-food-security-nutrition/en/. Acesso em: 30 set. 2019.

.Organização das Nações Unidas para Agricultura e Alimentação. O Estado da Segurança Alimentar e Nutricional no Brasil: Um Retrato Multidimensional - Relatório 2014. Brasília, 2014. Disponível em: https://www.fao.org.br/download/SO FI_p.pdf. Acesso em: 22 nov. 2018.

.Food and Agriculture Organization. Towards Food Security and Improved Nutrition: Increasing the Contribution of Forests and Trees. 2013. Disponível em: http://www.fao.org/3/i2969e/i2969e.pdf. Acesso em: 15 nov. 2018.

Alimentación escolar: Desarollo de programas sostentibles a partir del caso Brasileño. Curso semipresencial. Unidade 1. [ca: 2018].

FERRAZ, R; PRADO, R; PARRON, L; CAMPANHA, M. Marco Referencial em Serviços Ecossistêmicos. Brasília DF, EMBRAPA: 2019, p. 38-54.

FUNDAÇÃO CARGILL. Agricultura familiar é essencial para a segurança alimentar. Alimentação em Foco, 2016. Disponível em: https://alimentacaoemfoco.org.br/agriculturafamiliar-e-essencial-para-seguranca-alimentar/. Acesso em: 3 de junho 2020.

GLOBAL FOREST ATLAS. Industrial Agriculture. Disponível em: https://globalforestatlas.yale.edu/land-use/industrial-agriculture. Acesso em: 17 ago. 2019.

GUIDOTTI, V. Números detalhados do novo código florestal e suas implicações para os PRAs. $\quad$ IMAFLORA, 2017. Disponível em: <http://www.observatorioflorestal.org.br/content/uploads/2018/02/numeros_detalhados_codigo_ florestal_e_suas_implicacoes_para_os_pras.pdf.> Acesso em: 2 de nov. 2018.

HOFFMAN, R. A agricultura familiar produz $70 \%$ dos alimentos consumidos no Brasil? Segurança Alimentar e Nutricional, Campinas, v. 2, n.1, p. 417-421, 2014.

ICMBio. Guia de Políticas Públicas para Extrativistas das unidades de conservação: dedicando aos povos das florestas e das águas. 2017. Disponível em: http://www.icmbio.gov.br/portal/images/stories/comunicacao/publicacoes/publicacoes-

diversas/guia_de_politica_publicas_para_extrativistas_das_ucs.pdf

Acesso em: 20 de set. 2019.

INSTITUTO BRASILEIRO DE GEOGRAFIA E ESTATÍSTICA. IBGE. Brasil, 2017. Disponível em: https://teen.ibge.gov.br/. Acesso em: 28 de out. 2018.

Brasil, 2018. Disponível em: https://agenciadenoticias.ibge.gov.br/agencia-sala-deimprensa/2013-agencia-de-noticias/releases/10448-ibge-inicia-a-pesquisa-de-orcamentosfamiliares-pof-2017-2018

IPES Food. Too Big to Feed: Exploring the impacts of mega-mergers, consolidation and concentration of power in the agri-food sector. 2017. Disponível em:

http://www.ipes-food.org/_img/upload/files/Concentration_FullReport.pdf_Acesso em: 5 de jan. 2020. 
KEPPLE, A. Q.; SEGALL-CORREA, A. M. Conceituando e medindo segurança alimentar e nutricional. Ciência e Saúde Coletiva, v.1, n. 16, p. 187-199. 2011.

MALUF, R. Comer em tempos de pandemia e após. Jornal GGN. 2020. Disponível em: https://jornalggn.com.br/artigos/comer-em-tempos-de-pandemia-e-apos-por-renato-s-maluf/. Acesso em: 2020. Acesso em: 14 de jun. 2020.

Segurança Alimentar e Nutricional. Petrópolis: Editora Vozes Ltda., 2007.

MDSA. Ministério de Desenvolvimento Social e Agrário. Compras Públicas da Agricultura Familiar: Modalidade Compra Institucional (PAA). 2016.

MINTEL. Mercado de fast-food deve faturar mais de R\$50 bilhões em 2013. 2013. Disponível em: https://brasil.mintel.com/imprensa/alimentos-e-bebidas/mercado-de-fast-food-deve-faturarmais-de-r-50-bilhoes-em-2013 Acesso em: 15 ago. 2019.

MMA. Ministério do Meio Ambiente. Sistema Nacional de Unidades de Conservação. 2019. Disponível em: https://www.mma.gov.br/areas-protegidas/unidades-de-conservacao/sistemanacional-de-ucs-snuc.html Acesso em: 24 de maio, 2020.

Água para 123 milhões de brasileiros depende da Mata Atlântica. 2010. Disponivel em: $\quad$ https://www.mma.gov.br/informma/item/6635-agua-para-123-milhoes-de-brasileirosdepende-da-mata-atlantica. Acesso em: 15 de jan. 2020.

MONTEIRO, B. L. Políticas Públicas de Fortalecimento da Agricultura Familiar e Segurança Alimentar e Nutricional (SAN): Programa de Aquisição de Alimentos e o Programa Nacional de Alimentação Escolar no Município de Crato - CE. 2019. 120f. Dissertação (Mestrado Programa de Pós-graduação em Agricultura Orgânica) - Universidade Federal Rural do Rio de Janeiro, Seropédica - RJ, 2019.

MULHOLLEM, J. Double food production by 2050? Not so fast. Futurity, 2017. Disponível em: https://www.futurity.org/food-production-2050-1368582-2/ Acesso em: 15 de fev. 2020.

NEVES, D. C. Análise de Políticas Públicas Intersetoriais de Fortalecimento da Agricultura Familiar e de Segurança Alimentar e Nutricional no Brasil e o caso de um município do Espírito Santo. 2018. 104f. Dissertação (Mestrado em Programa de Pós-graduação em Práticas de Desenvolvimento Sustentável) - Universidade Federal Rural do Rio de Janeiro. 2018.

NEVES, D. C.; TABAI, K. C. A importância da intersetorialidade no Programa Nacional de Alimentação Escolar na região centro sul do Espírito Santo - Brasil. In: Helton Rangel Coutinho Junior (Org.). Fenomenologia e cultura: identidades e representações sociais. Ponta Grossa: Editora Athena, p. 78-90, 2020.

ONU. Policy Brief: The Impact of COVID-19 on Food Security and Nutrition. 2020. Disponivel em:

https://www.un.org/sites/un2.un.org/files/sg_policy_brief_on_covid_impact_on_food_security.p df. Acesso em: 19 abril 2020.

ORGANIZAÇÃO DAS NAÇÕES UNIDAS - ONU. Agenda 2030. 2015. Disponível em: http://www.agenda2030.com.br/. Acesso em: 10 dez. 2019.

RESENDE, C; SCARANO, F; ASSAD, C; JOLY, C; METZGER, J; STRASSBURG, B; TABARELLI, M; FONSECA, G; MITTERMEIR, R. From hotspot to hopespot: An opportunity 
for the Brazilian Atlantic Forest. Perspectives in Ecology and Conservation, v. 16, n. 4, p. 208214, 2018.

SHILOMBOLENI, H. OWAYGEN, M; DE PLAEN, R; MANCHUR, W; HUSAK, L. Scaling up innovations in smallholder agriculture: Lessons from the Canadian international food security research fund. Agricultural Systems, n.175, p. 58-65, 2019. Disponível em: https://cgspace.cgiar.org/handle/10568/101492. Acesso em: 18 de ago. 2020.

SOARES, K; NETO, J; OLIVEIRA, J; MARQUES, J; SANTOS, D. Políticas públicas: um estudo sobre o programa Rio Rural. 2013. Disponível em: https://seminariodeintegracao.ucamcampos.br/wp-content/uploads/2013/11/xii-seminario-integracao-2013-katia-macabu-de-sousasoares.pdf. Acesso em: 3 de abr. 2020.

SOS MATA ATLÂNTICA. Aqui tem mata. 2019. Disponível em: https://www.aquitemmata.org.br/\#/busca/rj/State\%20of\%20Rio\%20de\%20Janeiro/Duque\%20de \%20Caxias. Acesso em: 14 mar. 2020.

.Lei da Mata Atlântica. 2020. Disponível em: https://www.sosma.org.br/politicas/lei-damata-atlantica/. Acesso em: 14 mar. 2020.

SUNDERLAND, T; POWELL, B; ICKOWITZ, A; FOLI, S; PINEDO-VASQUEZ, M; NASI, R; PADOCH, C. Food security and nutrition: the role of forests. Bogor: CIFOR, 2013. Disponível em: http://www.cifor.org/publications/pdf_files/WPapers/DPSunderland1301.pdf. Acesso em: 5 de jan. 2020.

TABAI, K.C. A Segurança Alimentar e Nutricional no contexto da intersetorialidade. In: Denise R. Perdomo Azeredo (Org.). Inocuidade dos Alimentos. São Paulo: Ed. Atheneu, p. 19 - 30, 2017.

TABAI, K. C. Políticas de segurança alimentar e saúde pública. In: Lúcia Aparecida Valadares Sartório. (Org.). Sustentabilidade: qualidade de vida, economia alternativa e educação. 1a. ed. Nova Iguaçu: Editora Entorno, v. 1, p. 137-156, 2018.

TRIELLI, D; PRENGAMAN, P; DILORENZO, S. Millions return to poverty in Brazil as 'boom' decade erodes. Rio de Janeiro: The Seattle Times, 2017. Disponível em: https://www.seattletimes.com/business/millions-return-to-poverty-in-brazil-eroding-boomdecade/. Acesso em 1 jul. 2019.

VALENTE, J. Obesidade atinge quase $20 \%$ da população brasileira, mostra pesquisa. Agência Brasil, Brasília, 18 de junho de 2018. Disponível em: https://agenciabrasil.ebc.com.br/saude/noticia/2018-06/obesidade-atinge-quase-um-em-cadacinco-brasileiros-mostra-pesquisa_Acesso em: 09 de nov. 2019.

VIRA, B; WILDBURGER, C; MANSOURIAN, S. Forests, frees and landscapes for food security and nutrition: contributing to the "zero hunger challenge." Austria: International Union of Forest Research Organizations, 2015. 